OPEN ACCESS

Edited by:

Valeria Novelli,

Catholic University of the Sacred

Heart, Italy

Reviewed by:

Marina Cerrone,

New York University School of

Medicine, United States

Oscar Campuzano,

Hospital Clínic de Barcelona, Spain Minoru Horie,

Shiga University of Medical

Science, Japan

*Correspondence:

Maaike Alaerts

maaike.alaerts@uantwerpen.be

†These authors share last authorship

Specialty section:

This article was submitted to Cardiovascular Genetics and Systems

Medicine,

a section of the journal Frontiers in Cardiovascular Medicine

Received: 03 April 2020 Accepted: 04 June 2020

Published: 24 July 2020

Citation:

Nijak A, Labro AJ, De Wilde H, Dewals W, Peigneur S, Tytgat J, Snyders $D$, Sieliwonczyk E, Simons $E$, Van Craenenbroeck E, Schepers D, Van Laer L, Saenen J, Loeys B and

Alaerts M (2020) Compound Heterozygous SCN5A Mutations in Severe Sodium Channelopathy With Brugada Syndrome: A Case Report.

Front. Cardiovasc. Med. 7:117. doi: 10.3389/fcrm.2020.00117

\section{Compound Heterozygous SCN5A Mutations in Severe Sodium Channelopathy With Brugada Syndrome: A Case Report}

\author{
Aleksandra Nijak ${ }^{1}$, Alain J. Labro' ${ }^{2}$, Hans De Wilde ${ }^{3,4}$, Wendy Dewals ${ }^{3}$, Steve Peigneur ${ }^{5}$, \\ Jan Tytgat ${ }^{5}$, Dirk Snyders ${ }^{2}$, Ewa Sieliwonczyk ${ }^{1}$, Eline Simons ${ }^{1}$, \\ Emeline Van Craenenbroeck ${ }^{6}$, Dorien Schepers ${ }^{1}$, Lut Van Laer ${ }^{1}$, Johan Saenen ${ }^{6}$, \\ Bart Loeys ${ }^{1,7 \dagger}$ and Maaike Alaerts ${ }^{1 * \dagger}$ \\ ${ }^{1}$ Center of Medical Genetics, Antwerp University Hospital, University of Antwerp, Antwerp, Belgium, ${ }^{2}$ Laboratory of \\ Molecular, Cellular and Network Excitability, Department of Biomedical Sciences, University of Antwerp, Antwerp, Belgium, \\ ${ }^{3}$ Department of Paediatric Cardiology, Antwerp University Hospital, Antwerp, Belgium, ${ }^{4}$ Department of Invasive Cardiology \\ and Electrophysiology, Ghent University Hospital, Ghent, Belgium, ${ }^{5}$ Toxicology and Pharmacology, University of Leuven (KU \\ Leuven), Leuven, Belgium, ${ }^{6}$ Department of Cardiology, Antwerp University Hospital, University of Antwerp, Antwerp, \\ Belgium, ${ }^{7}$ Department of Human Genetics, Radboud University Medical Centre, Nijmegen, Netherlands
}

Aims: Brugada syndrome $(\mathrm{BrS})$ is an inherited cardiac arrhythmia with an increased risk for sudden cardiac death (SCD). About $20 \%$ of BrS cases are explained by mutations in the SCN5A gene, encoding the main cardiac sodium $\mathrm{Na}_{v} 1.5$ channel. Here we present a severe case of cardiac sodium channelopathy with BrS caused by SCN5A compound heterozygous mutations. We performed a genetic analysis of SCN5A in a male proband who collapsed during cycling at the age of 2 years. Because of atrial standstill, he received a pacemaker, and at the age of 3 years, he experienced a collapse anew with left-sided brain stroke. A later ECG taken during a fever unmasked a characteristic BrS type-1 pattern. The functional effect of the detected genetic variants was investigated.

Methods and Results: Next-generation sequencing allowed the detection of two SCN5A variants in trans: c.4813+3_4813+6dupGGGT-a Belgian founder mutation-and c.4711 T>C, p.Phe1571Leu. A familial segregation analysis showed the presence of the founder mutation in the proband's affected father and paternal aunt and the de novo occurrence of the p.Phe1571Leu. The functional effect of the founder mutation was previously described as a loss-of-function. We performed a functional analysis of the p.Phe571Leu variant in HEK293 cells alone or co-expressed with the $\beta_{1}$-subunit. Compared to the SCN5A wild type, p.Phe1571Leu displayed a hyperpolarizing shift in the voltage dependence of inactivation (loss-of-function), while the activation parameters were unaffected. Using the peptide toxin nemertide $\alpha-1$, the variant's loss-of-function effect could be restored due to a toxin-dependent reduction of channel inactivation. 
Conclusion: This is the first report providing support for the pathogenicity of the p.Phe1571Leu SCN5A variant which, together with the c.4813+3_4813+6dupGGGT founder mutation, explains the severity of the phenotype of cardiac sodium channelopathy with BrS in the presented case.

Keywords: Brugada syndrome, cardiac arrhythmia, SCN5A, case report, compound heterozygosity

\section{INTRODUCTION}

Brugada syndrome $(\mathrm{BrS})$ is an inherited cardiac arrhythmia with a significant risk for sudden cardiac death (SCD) and a prevalence of 1:2,000 in the general population (1). The disease is diagnosed based on a specific ECG pattern with distinct ST-segment elevation in the right precordial leads $(2,3)$. The disorder is predominantly explained by mutations in SCN5A (20$25 \%$ of all cases), encoding the $\alpha$-subunit of the cardiac voltagegated sodium channel $\mathrm{Na}_{\mathrm{v}} 1.5$. Currently, over 20 genes encoding other cardiac channels as well as their accessory proteins are linked to $\operatorname{BrS}(2,4,5)$.

Cardiac action potential generation and conduction velocity in the ventricles rely primarily on the availability of $\mathrm{Na}_{\mathrm{v}} 1.5$ channels $(3,6)$, responsible for a fast depolarization of the cardiomyocyte membrane $(7,8) . \mathrm{Na}_{\mathrm{v}} 1.5$ is a pseudo-tetramer consisting of four repetitive transmembrane domains (DI-IV), containing six transmembrane-spanning segments each (S1S6), with segments S1-S4 forming the 'voltage sensing domain (VSD)'. The VSDs of DI to DIII control the channel opening and closure (activation process), whereas the VSD of DIV regulates the channel inactivation $(3,9,10)$. An accessory $\beta_{1}$-subunit binds covalently to the $\alpha$-subunit, with variable effects on the activation kinetics (11). BrS is associated with a loss-of-function of $\mathrm{Na}_{\mathrm{v}} 1.5$, resulting in reduced sodium current $\left(I_{\mathrm{Na}}\right)$, impaired channel kinetics, or trafficking (35). Several reports show that heterozygous SCN5A variants cause a BrS phenotype with variable expressivity, ranging from asymptomatic to recurrent arrhythmias and SCD. In addition, they can lead to cardiac conduction disease, sick sinus syndrome, dilated cardiomyopathy, and familial atrial fibrillation or an "overlap syndrome" of these entities, together grouped as cardiac sodium channelopathies. Interestingly, second-hit mutations in genes encoding the auxiliary subunits of $\mathrm{Na}_{\mathrm{v}} 1.5$ or compound heterozygous mutations in SCN5A tend to cause more severe phenotypes (4-6).

Here we present a patient with a severe phenotype of cardiac sodium channelopathy with BrS phenotype presenting in early childhood due to compound heterozygous SCN5A mutations. One of the variants, c.4813+3_4813+6dupGGGT-a Belgian founder mutation causing cardiac conduction defects and/or BrS in $83 \%$ of carriers (Sieliwonczyk et al., under review), segregates in the paternal family. This splice site mutation results in the deletion of 32 amino acids $(1,572$ to 1,604$)$ in S2 and S3 of DIV of $\mathrm{Na}_{\mathrm{v}} 1.5$ with a loss-of-function of the channel, which is observed as the absence of sodium current when expressed in human embryonal kidney TSA cells $(12,13)$. We hypothesize that the second de novo variant, c.4711T $>$ C (p.Phe1571Leu), located in S2 of DIV, aggravates the phenotype in the proband. In this study, we functionally characterize this p.Phe1571Leu variant. We provide evidence for a loss-of-function effect which, in co-occurrence with the Belgian founder mutation, most likely explains the severity of the observed phenotype.

\section{MATERIALS AND METHODS}

\section{Mutation Analysis of SCN5A}

Genomic DNA was extracted from whole blood using standard procedures. Genetic testing of SCN5A was performed using an in-house developed cardiac arrhythmia gene panel (14). Sanger sequencing was used to validate the variants and perform familial segregation analysis. This study was carried out in accordance with the recommendations of the Ethics Committee of Antwerp University Hospital. All subjects gave written informed consent in accordance with the Declaration of Helsinki.

\section{Site-Directed Mutagenesis and Transfection of HEK293 Cells}

WT human SCN5A cDNA was cloned into the pSP64T plasmid and human $S C N 1 B$ (the $\beta_{1}$-subunit) cDNA into a pRcCMV plasmid. The p.Phe1571Leu variant was introduced in SCN5A using the QuickChange Site-Directed Mutagenesis Kit (Life Technologies) and a primer set that contained the variant (Eurogentec S.A.). The variant SCN5A p.Phe1571Leu plasmid was obtained by amplification in XL2 blue cells (Agilent Technologies) and subsequently purified (purification kit, Macherey-Nagel). The presence of the desired and absence of additional mutation(s) was confirmed by sequencing.

HEK293 cells were transiently transfected with WT SCN5A (expressing $\left.\mathrm{Na}_{\mathrm{v}} 1.5\right)$ or the p.Phe1571Leu variant $\left(\mathrm{Na}_{\mathrm{v}} 1.5\right.$ F1571L) alone or co-expressed in a 1:1 mass ratio with SCN1B using Lipofectamine 2000 (Life Technologies). In every condition, the pEGFP1-N1 plasmid was co-transfected to visualize the transfected cells for electrophysiological analysis. The cells were grown in Dulbecco's Modified Eagle Medium supplemented with $10 \%$ fetal bovine serum and $1 \%$ penicillin/streptomycin (Life Technologies). The cells were placed in a $5 \% \mathrm{CO}_{2}$ incubator at $37^{\circ} \mathrm{C}$ for $48 \mathrm{~h}$ prior to the patch-clamp recordings.

\section{Electrophysiological Recordings}

Whole-cell patch-clamp recordings were performed at room temperature $\left(20-22^{\circ} \mathrm{C}\right)$ using an Axopatch 200B amplifier and a pClamp 10.7/Digidata 1440A acquisition system (Axon Molecular Devices). Patch-pipettes with a resistance between 1 and $1.5 \mathrm{M} \Omega$ were pulled from $1.2-\mathrm{mm}$ borosilicate glass 
capillaries (World Precision Instruments, Inc.) using a P-2000 puller (Sutter Instrument Co.). The pipettes were filled with an intracellular solution containing (in $\mathrm{mM}$ ): $4 \mathrm{NaCl}, 106 \mathrm{KCl}, 5$ $\mathrm{K}_{2} \mathrm{ATP}, 2 \mathrm{MgCl}_{2}, 5 \mathrm{~K}_{4} \mathrm{BAPTA}$, and 10 HEPES adjusted to $\mathrm{pH}$ 7.2 with $\mathrm{KOH}$. The cells were continuously superfused with a bath solution (ECS) containing (in $\mathrm{mM}$ ): $145 \mathrm{NaCl}, 4 \mathrm{KCl}$, $5.3 \mathrm{CaCl}_{2}, 1 \mathrm{MgCl}_{2}, 10$ HEPES, and 10 glucose ( $\mathrm{pH} 7.35$ with $\mathrm{NaOH}$ ). For the toxin experiments, the nemertide 1- $\alpha$ synthetic peptide was directly dissolved in ECS at a concentration of $5 \mu \mathrm{M}$ and applied near the patched cell using a pressurized fast-perfusion system.

$I_{\mathrm{Na}}$ was recorded by step depolarization for $20 \mathrm{~ms}$ to different potentials between -120 and $+40 \mathrm{mV}$, from a holding potential of $-130 \mathrm{mV}$. Current-voltage relations (in $\mathrm{pA} / \mathrm{pF}$ ) were obtained by normalizing the peak $I_{\mathrm{Na}}$ amplitude to the cell capacitance and plotting these values as a function of the applied potential. Normalized conductance-voltage (G$V$ ) curves were obtained by approximating the linear part of the current-voltage relation with the function $I=$ $G_{\text {max }}^{*}\left(V_{\text {applied }}-V_{\text {reversal }}\right)$ to determine the maximal conductance $G_{\max }$. Dividing the data points of the current-voltage relation by the calculated maximum current at that voltage, using $G_{\max }$, yielded the $G-V$ relation. Activation and inactivation kinetics were determined by fitting the activating part or decay of $I_{\mathrm{Na}}$ with a single exponential function. The voltage dependence of inactivation was determined by stepping after a $500-\mathrm{ms}$ pre-pulse, ranging from -135 to $-30 \mathrm{mV}$, to a $-10-\mathrm{mV}$ test pulse to determine the amount of channel inactivation. The voltage dependence of the inactivation curves were obtained by plotting the normalized $I_{\mathrm{Na}}$ amplitude upon the test pulse against the corresponding pre-pulse potential. The recovery from inactivation was investigated upon a 500$\mathrm{ms}$ conditioning pre-pulse to induce inactivation. The recovery was determined by stepping after the pre-pulse for variable time to $-130 \mathrm{mV}$, a potential that recovers inactivation, followed by $-10 \mathrm{mV}$ pulse to evaluate the $I_{\mathrm{Na}}$ amplitude, which is a measure for the channels that have recovered. The speed of recovery from inactivation was evaluated by normalizing the $I_{\mathrm{Na}}$ elicited upon the $-10 \mathrm{mV}$ pulse to the maximum $I_{\mathrm{Na}}$. These normalized values were plotted as a function of the duration at $-130 \mathrm{mV}$, and this relation was approximated with a single exponential function.

Currents, after passing a $5-\mathrm{kHz}$ low-pass filter, were digitized at a sampling rate of $10 \mathrm{kHz}$. Recordings were discarded from analysis if the remaining voltage error, originating from series resistance error, exceeded $5 \mathrm{mV}$ after compensation.

\section{Data Analysis}

To obtain the midpoint potential $\left(V_{1 / 2}\right)$ and the slope factor $\left(V_{\mathrm{s}}\right)$ for the voltage dependence of activation and of inactivation, the $G-V$ and voltage dependence of the inactivation curves were fitted with a Boltzmann equation: $f(V)=\frac{I_{\max }}{1+e^{-\left(V-V_{1 / 2}\right) / V_{s}}}$.

Data are reported as mean \pm standard error of mean (SEM) with $n$ as the number of cells analyzed. A comparison between the WT and the variant was performed with two-tailed Student's $t$-test. A $P$-value of $\leq 0.05$ indicates statistical significance (Systat Software Inc.).

\section{CASE DESCRIPTION AND DIAGNOSTIC ASSESSMENT}

\section{Clinical Presentation of Index Patient and Available Family Members}

A 20-months-old boy was admitted to a hospital emergency service after his collapse during cycling. Based on the ECG, he was diagnosed with sick sinus syndrome (SSS) with junctional escape (Figure 1B). A DDD-pacemaker was implanted, and during the implantation, the dilated atria were electrically inactive, leading to the diagnosis of atrial standstill. A DNA sample was collected for molecular diagnostics.

During recovery, he experienced a collapse anew, caused by a thrombus which led to a left-sided brain stroke. The echocardiography showed left atrial spontaneous echocardiographic contrast but no obvious thrombi. Although during follow-up no ventricular tachyarrhythmias were documented, an ECG taken during fever $\left(39^{\circ} \mathrm{C}\right)$ unmasked the characteristic BrS type-1 pattern (Figure 1C), and the boy received an endovascular VVI-ICD as there is a high estimated risk of developing ventricular arrhythmias (timeline: Figure 1A).

The father had a history of syncope at the age of 30 . His ajmaline challenge test was negative, but an ECG taken during a fever episode showed a BrS coved-shape ECG pattern (Figures 1D,E). The sister of the father was diagnosed with an ajmaline-induced BrS type-1 ECG pattern (Figure 1F).

\section{Molecular Genetics}

Two SCN5A variants were identified in the index patient: c. $4813+3 \_4813+6$ dupGGGT, a Belgian founder mutation, and c. $4711 \mathrm{~T}>\mathrm{C}$ p. (Phe1571Leu). Since both SCN5A variants are separated by only 102 base pairs, we could derive from the sequence reads that they are never located on the same allele (in trans). No other variants of interest were detected with the PED MASTR Plus gene panel. A familial segregation analysis revealed the founder mutation in the proband's father (II:3) and paternal aunt (II:2) and de novo occurrence of the p.Phe1571Leu variant in the index patient (III:1) (Figure 1G).

The founder mutation was previously shown to cause a loss-of-function of the $\mathrm{Na}_{\mathrm{v}} 1.5$ channel (13) and is classified as a pathogenic variant (15). p.Phe1571Leu is absent from the GnomAD database [gnomad.broadinstitute.org (16)], whereas one carrier is reported in the TOPMED sample collection (dbSNP rs1369632373; nhlbiwgs.org). Phenylalanine at position 1,571 is highly conserved between species (Figure 2A), and in silico prediction on the functional impact of the variant is possibly damaging (MutationTaster, SIFT, PolyPhen; ENST00000413689.5). This initially led to the classification of this variant as a variant of uncertain significance (VUS) (15).

\section{Electrophysiological Characteristics}

To determine if this VUS contributes to the severe phenotype observed in our index patient, the $\mathrm{Na}_{\mathrm{v}} 1.5 \mathrm{WT}$ and $\mathrm{Na}_{\mathrm{v}} 1.5-\mathrm{F} 1571 \mathrm{~L}$ variant and combinations with the WT $\beta_{1}$-subunit $\left(\mathrm{Na}_{\mathrm{v}} 1.5+\right.$ 


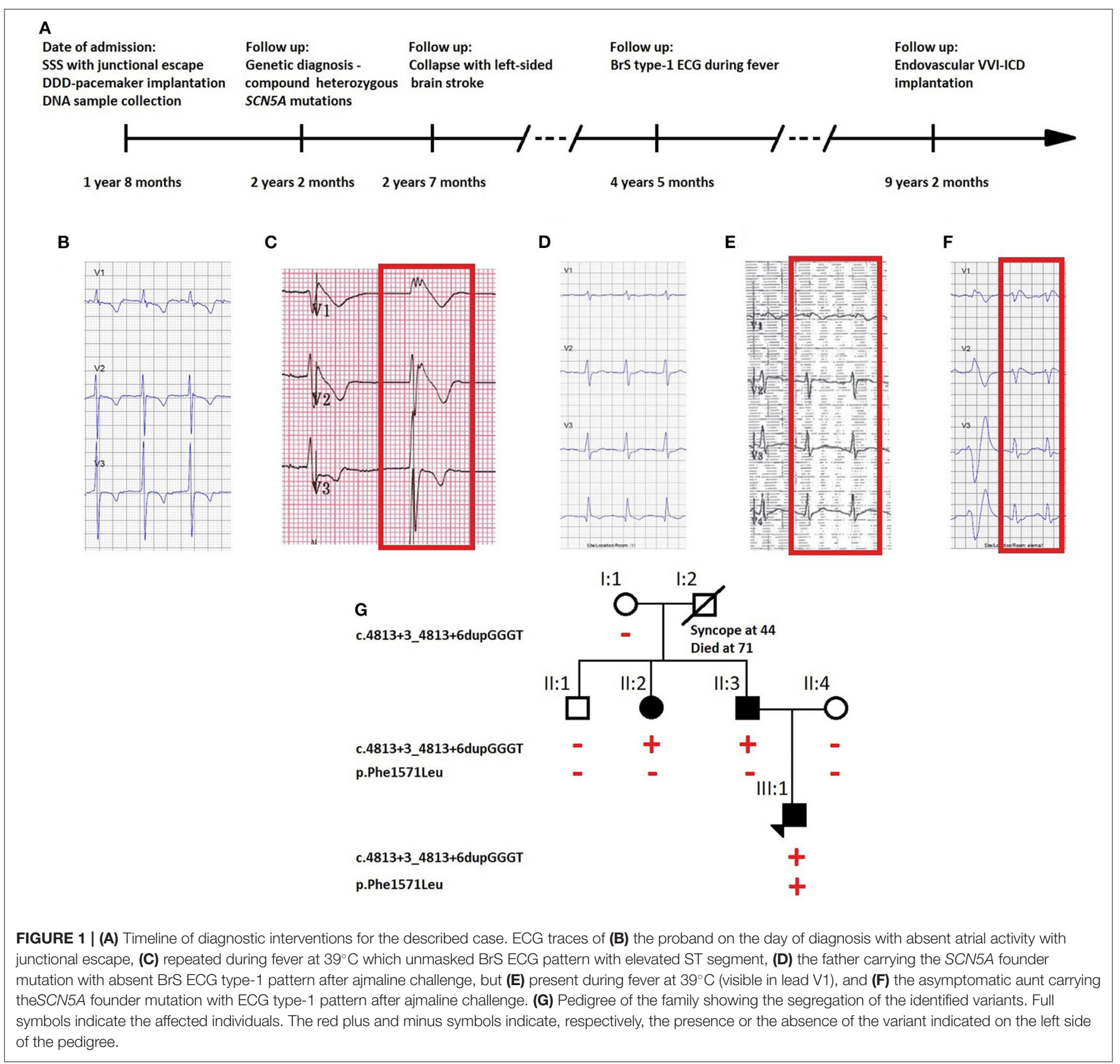

$\beta_{1}$ and $\left.\mathrm{Na}_{\mathrm{v}} 1.5-\mathrm{F} 1571 \mathrm{~L}+\beta_{1}\right)$ were expressed in HEK293 cells to assess the functional effect of the variant. The current-voltage (I$V)$ relationship showed that the current densities for the $\mathrm{Na}_{\mathrm{v}} 1.5$ and $\mathrm{Na}_{\mathrm{v}} 1.5-\mathrm{F} 1571 \mathrm{~L}$, either expressed alone or in presence of $\beta_{1}$, did not differ (Figures $2 \mathbf{B}, \mathbf{C}$ ). The activation kinetics as well as the voltage dependence of channel activation ( $G-V$ curves) did not show significant differences, yielding a $V_{1 / 2}$ of -13.8 \pm 1.7 and $-14.9 \pm 0.9 \mathrm{mV}$, with slope factors of $14.5 \pm 2.4$ and $14 \pm 1.3 \mathrm{mV}$ for $\mathrm{Na}_{\mathrm{v}} 1.5$ and $\mathrm{Na}_{\mathrm{V}} 1.5-\mathrm{F} 1571 \mathrm{~L}$, respectively (Figures 2D,E). These values did not change significantly in the presence of $\beta_{1}$, yielding $G-V$ curves with a $V_{1 / 2}$ of -12 \pm 0.8 and $-14.7 \pm 1.1 \mathrm{mV}$, with slope factors of $16.1 \pm 1$ and $11.7 \pm 1.7 \mathrm{mV}$ for $\mathrm{Na}_{\mathrm{v}} 1.5+\beta_{1}$ and $\mathrm{Na}_{\mathrm{v}} 1.5-\mathrm{F} 1571 \mathrm{~L}+$ $\beta_{1}$, respectively.

We subsequently analyzed the kinetics of inactivation, the voltage dependence of inactivation, and the recovery from inactivation (Figures 3A-E). From the inactivation time constant, we observed a 3 -fold slower inactivation $(P<0.001)$ for the variant $(1.96 \pm 0.12 \mathrm{~ms}$ at $0 \mathrm{mV}, n=7)$ compared to $\mathrm{Na}_{\mathrm{v}} 1.5$ $\mathrm{WT}(0.67 \pm 0.08 \mathrm{~ms}$ at $0 \mathrm{mV}, n=8)$ (Figure 3B). Co-expression with $\beta_{1}$ did not compensate this slowing, and $\mathrm{Na}_{\mathrm{v}} 1.5-\mathrm{F} 1571 \mathrm{~L}+$ $\beta_{1}(2.25 \pm 0.16 \mathrm{~ms}$ at $0 \mathrm{mV}, n=9)$ displayed 3.6-fold slower 


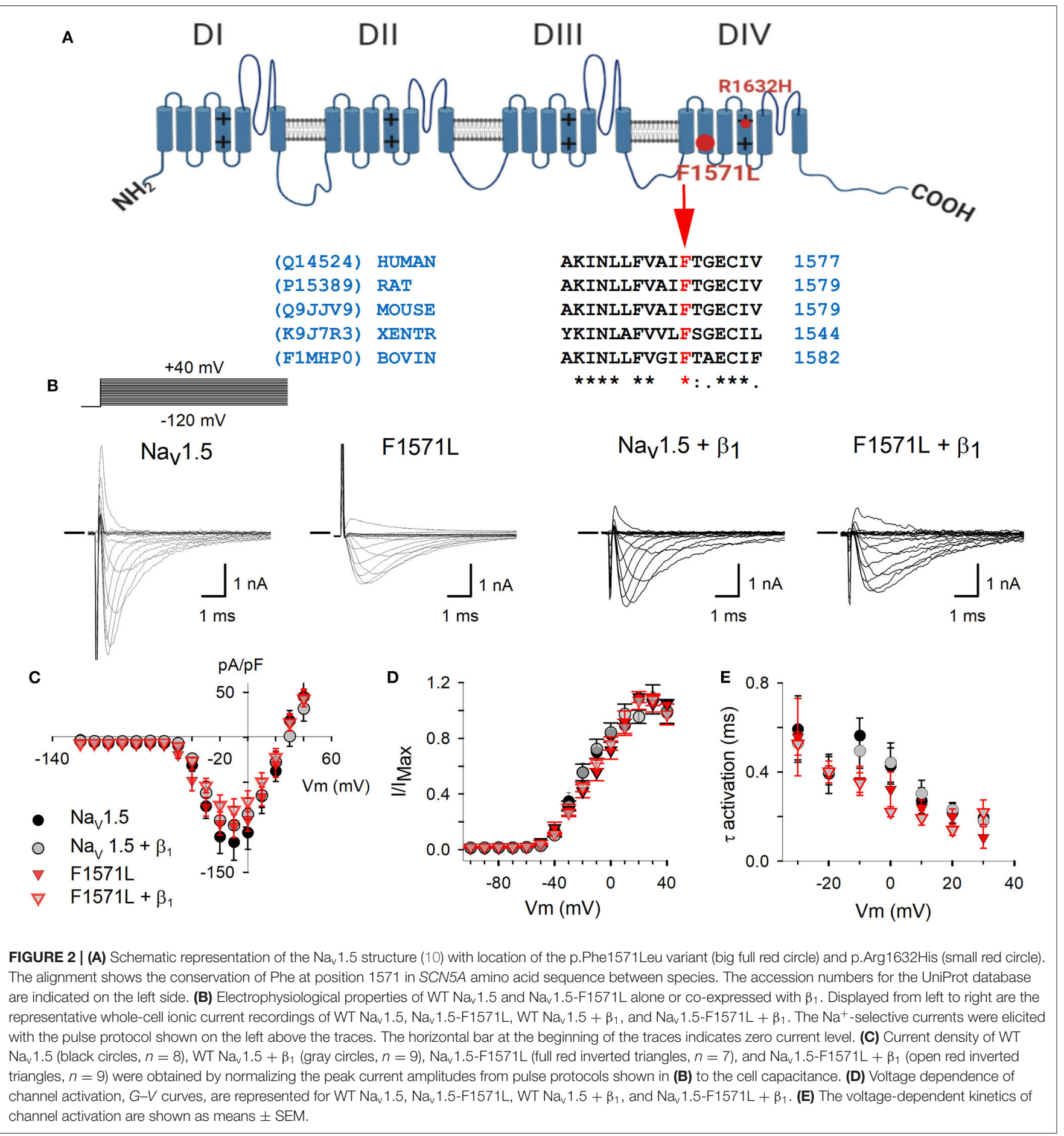

inactivation kinetics compared to WT $(0.63 \pm 0.02 \mathrm{~ms}$ at $0 \mathrm{mV}$, $n=9)(P<0.001)$.

Interestingly, the $\mathrm{Na}_{\mathrm{v}} 1.5-\mathrm{F} 1571 \mathrm{~L}$ variant displayed a significant $18-\mathrm{mV}$ hyperpolarizing shift in the voltage dependence of inactivation compared to WT $(P=0.001)$, yielding inactivation curves with a $V_{1 / 2}$ of $-104 \pm 3 \mathrm{mV}(n$
$=9)$ and $-86 \pm 3 \mathrm{mV}(n=5)$, combined with a slope factor of $7.6 \pm 0.8$ and $5.4 \pm 0.7 \mathrm{mV}$ for $\mathrm{Na}_{\mathrm{v}} 1.5-\mathrm{F} 1571 \mathrm{~L}$ and $\mathrm{Na}_{\mathrm{v}} 1.5$, respectively (Figure $3 \mathrm{C}$ ). Co-expression with the $\beta_{1}$ subunit did not rescue the effect of the variant, and $\mathrm{Na}_{\mathrm{v}} 1.5-\mathrm{F} 1571 \mathrm{~L}+\beta_{1}$ displayed a significant 8.3-mV hyperpolarizing shift compared to $\mathrm{Na}_{\mathrm{v}} 1.5+\beta_{1}(P=0.003)$, yielding inactivation curves with a $V_{1 / 2}$ 

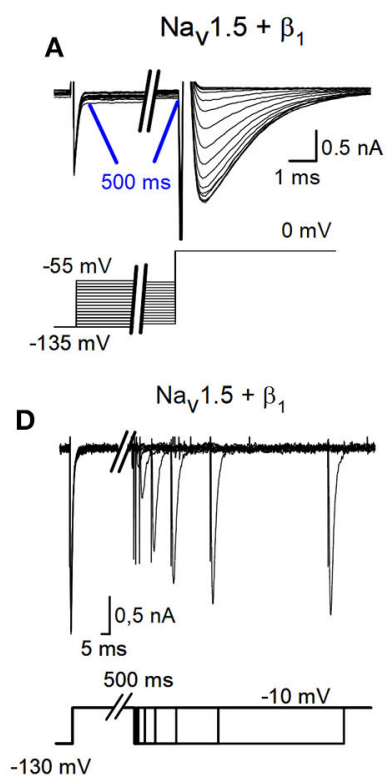
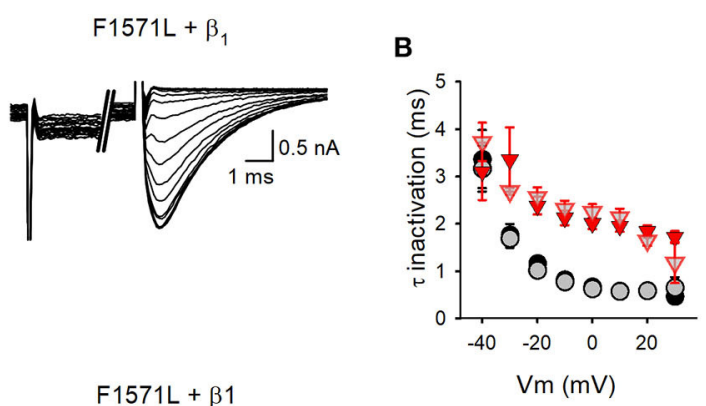

E

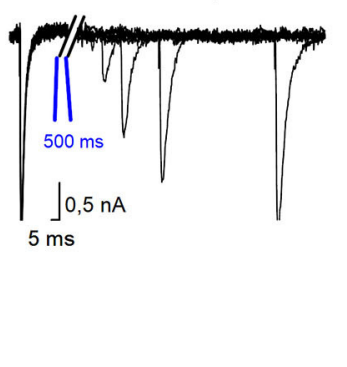

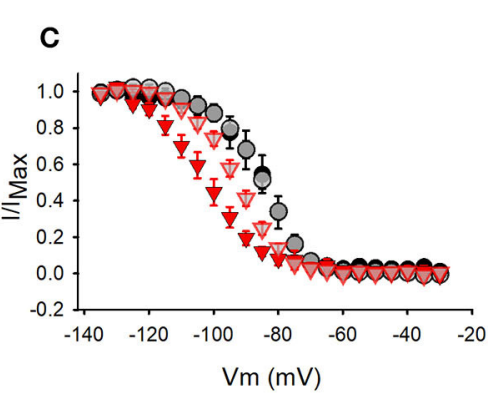

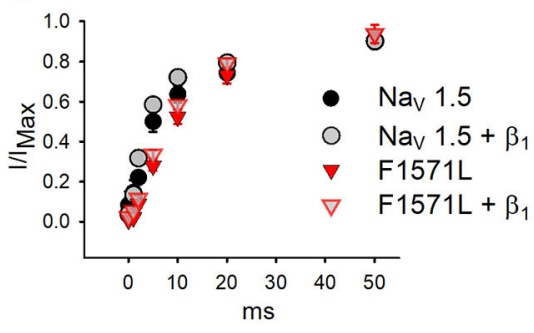

FIGURE 3 | Inactivation properties of WT Nav 1.5 and $\mathrm{Na}_{\mathrm{v}} 1.5-\mathrm{F} 1571 \mathrm{~L}$ alone or co-expressed with $\beta_{1}$. (A) Displayed from left to right are the representative whole-cell inactivation recordings of WT Nav $1.5+\beta_{1}$ and $\mathrm{Na}_{v} 1.5-\mathrm{F} 1571 \mathrm{~L}+\beta_{1}$. The / Na were elicited with the pulse protocol shown underneath the traces. (B) The time constants of channel inactivation for WT Nav 1.5 (black circles, $n=5$ ), WT Nav $1.5+\beta_{1}$ (gray circles, $n=12$ ), Nav $1.5-\mathrm{F} 1571 \mathrm{~L}$ (full red inverted triangles, $n=9$ ), and $\mathrm{Na}_{\mathrm{v}} 1.5-\mathrm{F} 1571 \mathrm{~L}+\beta_{1}$ (open red inverted triangles, $n=12$ ). The values shown are means $\pm \mathrm{SEM}$. (C) Voltage dependence of channel inactivation obtained by plotting the normalized current amplitudes at $-10 \mathrm{mV}$, elicited after $500 \mathrm{~ms}$ of conditioning pre-pulse depolarization, as a function of the pre-pulse potential. (D) Displayed from left to right are the representative whole-cell recordings of recovery from inactivation of WT Nav $1.5+\beta_{1}$ and $\mathrm{Na}_{v} 1.5-\mathrm{F} 1571 \mathrm{~L}+\beta_{1}$. The protocol used is shown underneath the traces. (E) Graph representing the recovery from inactivation, sampled after $500 \mathrm{~ms}$ from induction of inactivation.

of $-93 \pm 2 \mathrm{mV}(n=12)$ and $-84 \pm 2 \mathrm{mV}(n=12)$, combined with a slope factor of $7.2 \pm 0.5$ and $5.8 \pm 0.5 \mathrm{mV}$, respectively $(P$ $=0.04$ ).

As the onset of inactivation was slowed in the variant, we observed also a slowed recovery from inactivation. The time constants of recovery from inactivation revealed a slower recovery for the variant channel compared to WT $(P<0.001)$, which was not rescued by co-expression with the $\beta_{1}$ subunit $(P<0.001)\left[\mathrm{Na}_{\mathrm{v}} 1.5: 7.4 \pm 0.1 \mathrm{~ms}(n=6) ; \mathrm{Na}_{\mathrm{v}} 1.5-\mathrm{F} 1571 \mathrm{~L}:\right.$ $15.2 \pm 0.1 \mathrm{~ms}(n=12) ; \mathrm{Na}_{\mathrm{v}} 1.5+\beta_{1}: 5.2 \pm 0.2 \mathrm{~ms}(n=10)$; $\left.\mathrm{Na}_{\mathrm{v}} 1.5-\mathrm{F} 1571 \mathrm{~L}+\beta_{1}: 13 \pm 0.1 \mathrm{~ms}(n=15)\right]$ (Figures 3D,E).

As this patient's severe phenotype seems to be associated with $\mathrm{Na}_{\mathrm{v}} 1.5-\mathrm{F} 1571 \mathrm{~L}$ displaying a hyperpolarizing shift in the voltage dependence of inactivation, we explored if we could restore the variant's voltage dependence of inactivation toward WT values by drug/toxin addition. The peptide toxin nemertide $\alpha-1$ seemed to be a good candidate as it was reported to have a decelerating effect on the inactivation process of human sodium channels without influencing the parameters of activation and $I_{\mathrm{Na}}$ density (17). Two minutes of perfusion of $5 \mu \mathrm{M}$ of nemertide $\alpha-1$ induced a steady-state modification of $I_{\mathrm{Na}}$ inactivation of both $\mathrm{Na}_{\mathrm{v}} 1.5+\beta_{1}$ and the variant p.F1571L $+\beta_{1}$ (Figure 4A). Upon this nemertide $\alpha-1$ addition, we observed a 16 -fold slowing in the inactivation kinetics of $\mathrm{Na}_{\mathrm{v}} 1.5+\beta_{1}$; at $0 \mathrm{mV}$, the time constant of inactivation slowed from $0.47 \pm 0.04 \mathrm{~ms}$ in the absence of nemertide $\alpha-1$ to $7.62 \pm 1.18 \mathrm{~ms}$ with nemertide $\alpha-1 \quad(n=6 ; P=0.0002)$. The variant $\mathrm{Na}_{\mathrm{v}} 1.5-\mathrm{F} 1571 \mathrm{~L}+\beta_{1}$ also reported a significant 3fold slowing of inactivation $(P=0.002)$ displaying at $0 \mathrm{mV}$ a time constant of $2.22 \pm 0.57 \mathrm{~ms}$ in the absence of nemertide $\alpha-1$ and $5.82 \pm 0.68 \mathrm{~ms}$ in its presence $(n=6)$ (Figure $4 \mathrm{~B}$ ). Next, we investigated the voltage dependence of inactivation and observed no significant changes in the $V_{1 / 2}$ upon toxin addition for both $\mathrm{Na}_{\mathrm{v}} 1.5+\beta_{1}$ and $\mathrm{Na}_{\mathrm{v}} 1.5-\mathrm{F} 1571 \mathrm{~L}+\beta_{1}(P>0.5)$. In contrast, the slope factors became significantly shallower and amounted, after toxin modification, to $10.6 \pm 0.8 \mathrm{mV}(n=6)$ and $12.3 \pm 1.3 \mathrm{mV}(n=6)$ for $\mathrm{Na}_{\mathrm{v}} 1.5+\beta_{1}$ and $\mathrm{Na}_{\mathrm{v}} 1.5-\mathrm{F} 1571 \mathrm{~L}+$ $\beta_{1}$, respectively (Figures $4 \mathbf{C}, \mathbf{D}$ ). Due to the shallower slope, the amount of $\mathrm{Na}_{\mathrm{v}} 1.5-\mathrm{F} 1571 \mathrm{~L}+\beta_{1}$ channel inactivation is reduced at the physiological relevant resting membrane potential (i.e., around $-85 \mathrm{mV}$ ) upon nemertide $\alpha-1$ addition.

\section{DISCUSSION}

$\mathrm{BrS}$ is rarely observed in the pediatric population (18-20), and only $4.3 \%$ of symptomatic patients experience their first malignant ventricular arrhythmic event before the age of 16 years (21). Single heterozygous loss-of-function variants in SCN5A can cause BrS, cardiac conduction disease, sick sinus syndrome, dilated cardiomyopathy, and familial atrial fibrillation or manifest as an 'overlap syndrome' of these entities (22). When SCN5A is affected by two compound variants, this can result in a significant aggravation of the disease severity and/or earlier disease onset $(5,23-26)$. This was also observed in our proband who experienced his first syncope during physical activity at around the age of 2 years, probably caused by bradyarrhythmia in the setting of atrial standstill. Most of the similarly 


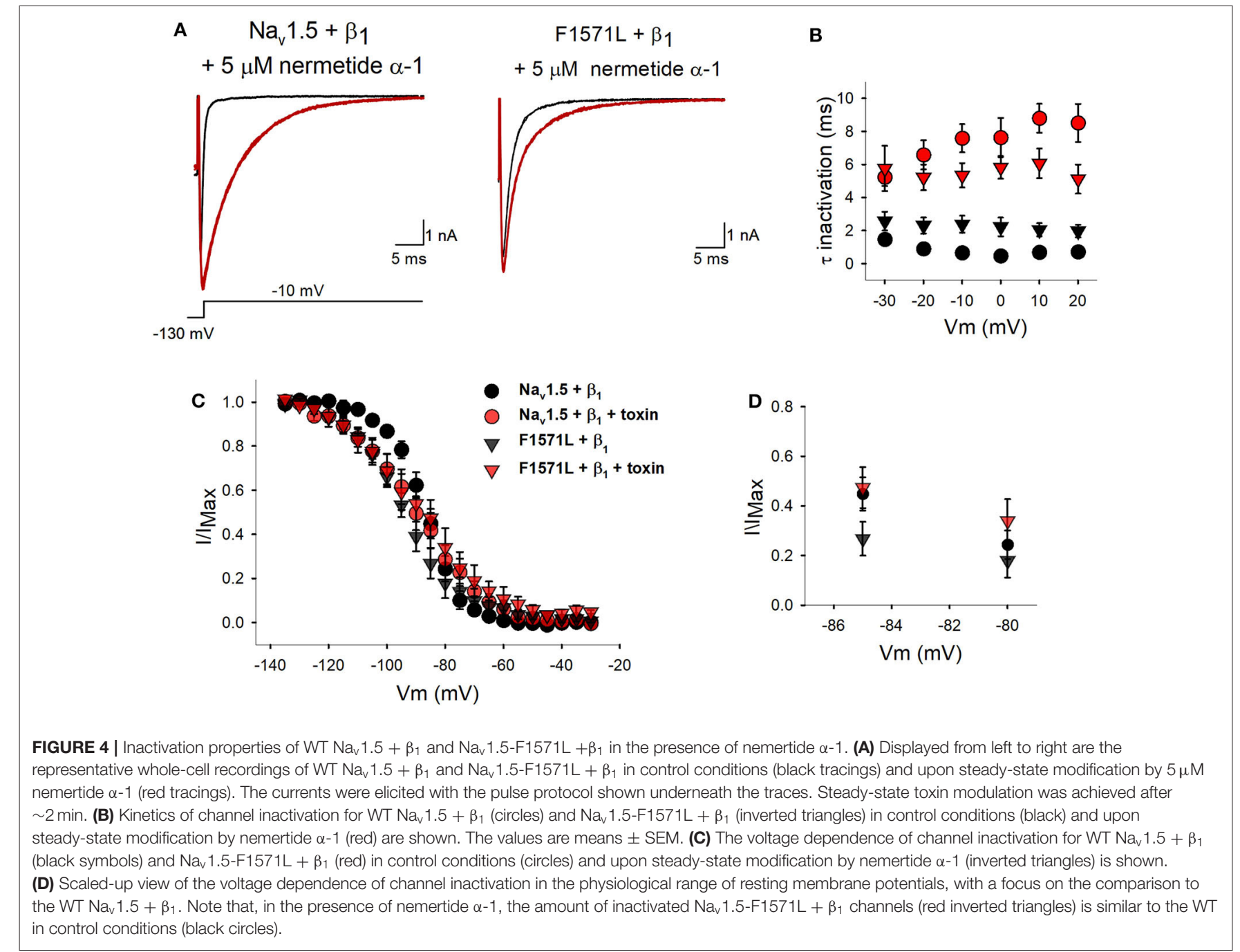

B

published patients presented with sinus node dysfunction $(5,23$, $24,26)$. Only Sacilotto et al. reported a patient presenting initially with atrial flutter and recurrent syncopes without spontaneous ventricular arrhythmia and who, similarly to our case, presented a spontaneous BrS type-1 ECG pattern during follow-up (24). Clinical interventions mostly encompass the implantation of a pacemaker $(5,23,24,26)$, with additional low-dose aspirin (24) or oral quinidine (23), and single patient received $\beta$-blockers without pacemaker implantation (25).

In the presented family, heterozygous carriers of the SCN5A Belgian founder mutation showed characteristic BrS type-1 ECG pattern either after sodium channel blocker challenge (II:2) or during fever conditions (II:3) but presented no symptoms (II:2) or syncope at the age of 30 years (II:3). The proband's second variant, p.Phe1571Leu, is a missense variant that we functionally modeled in HEK293 cells. Our experiments showed that p.Phe1571Leu does not affect current density, voltage dependence of channel activation, or activation kinetics (Figures 2C-E). However, it did impair the inactivation properties, as could be expected from the localization of the variant in the VSD of DIV, which is known to regulate channel inactivation (9). On the one hand, the variant slows down inactivation (Figure 3B), which would suggest a gain-of-function of the variant. This effect would rather be predicted to lead to a long-QT syndrome type 3 phenotype (4) but, on the other hand, the voltage dependence of inactivation of p.Phe1571Leu displays a significant hyperpolarizing shift (Figure 3C) which, in physiological conditions, results in a reduction of over $40 \%$ in the availability of $\mathrm{Na}_{\mathrm{v}} 1.5$ channels at rest (i.e., at $-85 \mathrm{mV}$ ). The significantly slowed recovery of the mutant channel (Figure 3E) further reduces the availability of the remaining channels, exacerbating the effect. This combination obviously leads to a loss-of-function of $I_{\mathrm{Na}}$, explaining the (aggravated) phenotype of cardiac sodium channelopathy with $\mathrm{BrS}$ in the patient.

Interestingly, an almost identical electrophysiological effect was reported for the SCN5A p.Arg1632His (R1632H) variant (5, 26), located in DIV S4 (Figure 2A) in proximity to p.Phe1571Leu. Slower inactivation kinetics, delayed recovery from inactivation, and a hyperpolarizing shift in voltage dependence of inactivation of similar magnitude $(20.7 \mathrm{mV})$ as we observed $(18 \mathrm{mV})$ were 
described (26). The heterozygous carriers of this variant had no symptoms, SSS, ajmalin-induced BrS (5), or first-degree AV block (25), while the compound heterozygous carriers (with second SCN5A variant) presented with early-onset SSS $(5,25)$. This supports the likely pathogenicity of the p.Phe1571Leu variant characterized in this study and its causal role in aggravating the phenotype of the presented case.

Also interesting is that another missense variant at the same amino acid location, p.Phe1571Cys, has been reported in a Brugada syndrome patient (27), but no functional analysis was performed. Although the resulting amino acid change is different, this could be supportive of our findings as well.

Our experiments with the toxin nemertide $\alpha$ - 1 showed that the WT channels were responding as expected as inactivation kinetics were slowed down. However, no depolarizing shift in the voltage dependence of inactivation was observed for the WT $\mathrm{Na}_{\mathrm{v}} 1.5+\beta_{1}$ as was observed for $\mathrm{Na}_{\mathrm{v}} 1.5$ expressed in Xenopus laevis oocytes (16). This might be because of a different cell type and/or the addition of the $\beta_{1}$-subunit, which seems to protect the cells from fluctuations in the voltage dependence of inactivation. Nevertheless, toxin addition resulted in a shallower voltage dependence of inactivation (i.e., larger slope factor value) such that the amount of inactivated $\mathrm{Na}_{\mathrm{v}} 1.5-\mathrm{F} 1571 \mathrm{~L}$ channels is reduced at the physiological resting membrane potential (Figures 4C,D). In the presence of toxin, the amount of available non-inactivated $\mathrm{Na}_{\mathrm{v}} 1.5-\mathrm{F} 1571 \mathrm{~L}+\beta_{1}$ channels rises from $18 \%$ without toxin to $\sim 36 \%$ (at $-85 \mathrm{mV}$ ), which is similar to the amount of available WT $\mathrm{Na}_{\mathrm{v}} 1.5+\beta_{1}$ channels. To our knowledge, this is the first report in which the use of a sodium channel activator toxin is proposed as a potential remedy for the pathogenic effect of a $S C N 5 A$ variant.

Based on these functional experiments, we conclude that the described p.Phe1571Leu variant is likely pathogenic (15) and, in the presented case, its de novo occurrence, together with the SCN5A Belgian founder mutation, explains the severe phenotype of cardiac sodium channelopathy with BrS.

\section{DATA AVAILABILITY STATEMENT}

The datasets presented in this study can be found in online repositories. The names of the repository/repositories and accession number(s) can be found below: https://www.ncbi.

\section{REFERENCES}

1. Postema PG. About Brugada syndrome and its prevalence. Europace. (2012) 14:925-8. doi: 10.1093/europace/eus042

2. Antzelevitch C. J wave syndromes: Brugada and early repolarization syndromes. Heart Rhythm. (2015) 12:1852-66. doi: 10.1016/j.hrthm. 2015.04.014

3. Bartos DC, Ripplinger CM. Ion channels in the heart. Compreh Physiol. (2015) 5:1423-64. doi: 10.1002/cphy.c140069

4. Bezzina CR, Priori SG. Genetics of sudden cardiac death. Circ Res. (2015) 116:1919-36. doi: 10.1161/CIRCRESAHA.116.304030

5. Robyns T, Van Casteren L, Corveleyn A, De Ravel T, Heidbuchel H, Willems R. Reduced penetrance and variable expression of SCN5A mutations and the importance of co-inherited genetic variants: case report and nlm.nih.gov/, SCV001190331 https://www.ncbi.nlm.nih.gov/, SCV001190333.

\section{ETHICS STATEMENT}

The studies involving human participants were reviewed and approved by Ethics Committee of the Antwerp University Hospital. Written informed consent to participate in this study was provided by the participants' legal guardian/next of kin. Written informed consent was obtained from the individual(s), and minor(s)' legal guardian/next of kin, for the publication of any potentially identifiable images or data included in this article.

\section{AUTHOR CONTRIBUTIONS}

$\mathrm{AN}, \mathrm{AL}, \mathrm{BL}$, and $\mathrm{MA}$ designed and planned the experimental framework. AN performed the experiments. AN, AL, and MA wrote the manuscript with critical input from all the authors. AN analyzed the data under the supervision of AL. JT and SP advised and provided the toxin for the functional experiments. HD, WD, $\mathrm{EV}, \mathrm{LV}$, and JS provided the clinical data of the index patient and family members.

\section{FUNDING}

This research was supported by funding from the University of Antwerp (GOA) and the Research Foundation-Flanders (FWO, Belgium, G.0356.17). BL and EV are senior clinical investigators of the FWO. BL holds a consolidator grant from the European Research Council (Genomia-ERC-COG-2017-771945). AN, ESim, and ESie hold Ph.D. fellowships of the FWO (1S24317N, $1 \mathrm{~S} 25318 \mathrm{~N}$, and $1192019 \mathrm{~N})$. DSc was supported by a postdoctoral fellowship of the FWO (grant number 12R5610N). JT was funded by GOC2319N and GOA4919N (FWO Vlaanderen) and CELSA/17/047 (BOF, KU Leuven). SP was a post-doctoral fellow supported by KU Leuven funding (PDM/19/164).

\section{ACKNOWLEDGMENTS}

We wish to thank the patient, the family members, and the staff from all units that participated in the study. doi: 10.1016/S0972-6292(16)30754-9

6. Baroni D. On the multiple roles of the voltage gated sodium channel B1 subunit in genetic disease. Front Pharmacol. (2015) 6:108. doi: 10.3389/fphar.2015.00108

7. Priest BT. Cardiac ion channels. Channels (Austin). (2015) 9:352-9. doi: $10.1080 / 19336950.2015 .1076597$

8. Medeiros-Domingo A, Iturralde Torres P, Tester DJ, Luna TT, Makielski JC, Ackerman MJ. Unique mixed phenotype and unexpected functional effect revealed by novel compound heterozygosity mutations involving SCN5A. Heart Rhythm. (2009) 6:1170-5. doi: 10.1016/j.hrthm.2009.04.034

9. Detta N, Salvatore F. The multi-faced aspects of the complex cardiac $\mathrm{Na}_{\mathrm{V}} 1.5$ protein in membrane function and pathophysiology. Biochim Biophys Acta. (2015) 1854:1502-9. doi: 10.1016/j.bbapap.2015.07.009 
10. Jiang D, Tonggu L, El-Din TMG, Lenaeus MJ, Zhao J, Yoshioka C, et al. Structure of the cardiac sodium channel. Cell. (2020) 180:122-34. doi: 10.1016/j.cell.2019.11.041

11. Zhu W, Varga Z, Schubert AR, Nerbonne JM, Silva JR. Mechanisms of noncovalent B subunit regulation of Nav channel gating. J Gen Physiol. (2017) 49:813-31. doi: 10.1085/jgp.201711802

12. Rossenbacker T, Schollen E, Kuiperi C, de Ravel TJL, Devriendt K, Matthijs G, et al. Unconventional intronic splice site mutation in SCN5A associates with cardiac sodium channelopathy. J Med Genet. (2005) 42:e29. doi: 10.1136/jmg.2004.029058

13. Hong K, Pollevick GD, Dumaine R, de Zutter M, Burashnikov E, Wu YS, et al. Cryptic 5' splice site activation in SCN5A associated with Brugada syndrome. J Mol Cell Cardiol. (2005) 38:555-60. doi: 10.1016/j.yjmcc.2004.10.015

14. Proost D, Vanderweyer G, Rotthier A, Alaerts M, Van Craenenbroeck EM, Van Crombruggen J, et al. Targeted next-generation sequencing of 51 genes involved in primary electrical disease. J Mol Diagn. (2017) 19:445-59. doi: 10.1016/j.jmoldx.2017.01.010

15. Richards S, Aziz N, Bale S, Bick D, Das S, Gastier-Foster J, et al. ACMG Laboratory Quality Assurance Committee, Standards and guidelines for the interpretation of sequence variants: a joint consensus recommendation of the American College of Medical Genetics and Genomics and the Association for Molecular Pathology. Genet Med. (2015) 17:405-24. doi: 10.1038/gim.2015.30

16. Karczewski LC, Francioli G, Tiao BB, Cummings J, Alföldi Q, Wang RL, et al. Variation across 141,456 human exomes and genomes reveals the spectrum of loss-of-function intolerance across human protein-coding genes. bioRxiv. (2019) 531210. doi: 10.1038/s41586-020-2308-7

17. Jacobsson E, Strand M, Peigneur S, Eriksson C, Loden H, Shariatgorji M, et al. Peptide ion channel toxins from the bootlace worm, the longest animal on Earth. Nat Sci Rep. (2017) 8:4596. doi: 10.1038/s41598-018-22305-w

18. Conte S, Dewals W, Sieira J, de Asmundis C, Ciconte G, Chierchia GB, et al. Drug-induced Brugada syndrome in children: clinical features, device-based management, and long-term follow-up. J Am Coll Cardiol. (2014) 63:2272-9. doi: 10.1016/j.jacc.2014.02.574

19. Andorin A, Behr ER, Denjoy I, Crotti L, Dagradi F, Jesel L, et al. Impact of clinical and genetic findings on the management of young patients with Brugada syndrome. Heart Rhythm. (2016) 13:1274-82. doi: 10.1016/j.hrthm.2016.02.013

20. Gonzalez Corcia MC, Sieira J, Sarkozy A, de Asmundis C, Chierchia GB, Hernandez Ojeda J, et al. Brugada syndrome in the young: an assessment of risk factors predicting future events. Europace. (2017) 19:1864-73. doi: 10.1093/europace/euw206
21. Milman A, Andorin A, Gourraud JB, Sacher F, Mabo P, Kim SH, et al. Age of first arrhythmic event in Brugada syndrome: data from the SABRUS (survey on arrhythmic events in Brugada syndrome) in 678 patients. Circ Arrhythm Electrophysiol. (2017) 10:e005222. doi: 10.1161/CIRCEP.117.005222

22. Chockalingam $\mathrm{P}$, Wilde A. The multifaceted cardiac sodium channel and its clinical implications. Heart. (2012) 98:1318-24. doi: 10.1136/heartjnl-2012-301784

23. Sacilotto L, Darrieux FC, Wulkan F, Oliveira TG, Hachul DT, Pereira AD, et al. Compound heterozygous SCN5A mutations in a toddler-are they associated with a more severe phenotype? Arq Bras Cardiol. (2017) 108:70-3. doi: 10.5935/abc.20170006

24. Baskar S, Clements D, Mayuga KA, Aziz PF. Compound heterozygous mutations in the SCN5A-encoded Nav1.5 cardiac sodium channel resulting in atrial standstill and His-Purkinje system disease. J Pediatr. (2014) 165:1050. doi: 10.1016/j.jpeds.2014.07.036

25. Bezzina CR, Groenewegen WA, Herfst LJ, van der Wal AC, Lam J, Jongsma $\mathrm{HJ}$, et al. Compound heterozygosity for mutations (W156X and R225W) in SCN5A associated with severe cardiac conduction disturbances and degenerative changes in the conduction system. Circ Res. (2003) 92:159-68. doi: 10.1161/01.RES.0000052672.97759.36

26. Benson DW, Dyment M, Knilans TK, Fish FA, Strieper MJ, Rhodes TH, et al. Congenital sick sinus syndrome caused by recessive mutations in the cardiac sodium channel gene (SCN5A). J Clin Invest. (2003) 112:1019-28. doi: 10.1172/JCI200318062

27. Kapplinger JD, Tester DJ, Alders M, Benito B, Berthet M, Brugada J, et al. An international compendium of mutations in SCN5A-encoded cardiac sodium channel in patients referred for Brugada syndrome genetic testing. Heart Rhythm. (2010) 7:33-46. doi: 10.1016/j.hrthm.2009.09.069

Conflict of Interest: The authors declare that the research was conducted in the absence of any commercial or financial relationships that could be construed as a potential conflict of interest.

Copyright (c) 2020 Nijak, Labro, De Wilde, Dewals, Peigneur, Tytgat, Snyders, Sieliwonczyk, Simons, Van Craenenbroeck, Schepers, Van Laer, Saenen, Loeys and Alaerts. This is an open-access article distributed under the terms of the Creative Commons Attribution License (CC BY). The use, distribution or reproduction in other forums is permitted, provided the original author(s) and the copyright owner(s) are credited and that the original publication in this journal is cited, in accordance with accepted academic practice. No use, distribution or reproduction is permitted which does not comply with these terms. 